ANFUSINA: JOURNAL OF PSYCHOLOGY

http://ejournal.radenintan.ac.id/index.php/anfusina

DOI: //dx.doi.org/10.24042/ajp.v3i1.6892

Volume 3, Nomor 1, April Tahun 2020

\title{
Metode Pilates Untuk Penurunan Kecemasan Ibu Hamil Pertama Trimester III
}

\author{
Dwi Surya Purwanti \\ STIKes YARSI Pontianak \\ latechoco_late@yahoo.com
}

\begin{abstract}
This research set out to investigate the effect of pilates method to reduce anxiety for pregnant women, especially in third trimester. Hypothesis proposed: there is anxiety difference for pregnant women in third quarter between control group and experimental group. Subject of research contains pregnant women who check their pregnancy at private childbirth clinic in Yogyakarta. On the basic of medical record data, it was obtained that eight pregnant women meeting research criteria, that was: first pregnancy and entered third trimester data collection methods used were personal quesioner, pregnancy anxiety scale. Analysis technique used U Mann - Whitney test. To see the differences of anxiety condition before and after treated with Pilates method in experimental group, Wilcoxon Rank Test was used. As results, it has been shown that $(Z=-1.964 ; p<$ 0.05). Experimental group's anxiety level is lower $($ mean $=62.33)$ than control group's anxiety level (mean $=100.33$ ). Experimental group, in particular, has been proved that movements in Pilates method for pregnancy were effective in reducing anxiety in facing first pregnancy in third trimester $(t=7.821 ; p<0.05)$ with mean before $=$ 95.00; mean after $=62.33$. So pilates method effective to reduce anxiety for pregnant women in third trimester.
\end{abstract}




\begin{abstract}
Abstrak
Penelitian ini bertujuan untuk mengetahui pengaruh metode pilates terhadap kecemasan pada ibu hamil pertama trimester III. Hipotesis yang diajukan adalah: Ada perbedaan kecemasan ibu hamil pertama trimester III antara kelompok kontrol yang tidak diberikan latihan gerakan pilates dengan kelompok eksperimen yang diberikan latihan gerakan pilates. Subjek penelitian ini adalah ibu hamil yang memeriksakan kehamilannya di klinik bersalin bidan swasta Yogyakarta. Ada 8 orang ibu hamil yang memenuhi kriteria sebagai subjek penelitian, yaitu: kehamilan pertama, memasuki trimester ketiga. Alat pengumpul data yang digunakan adalah Skala Kecemasan Kehamilan. Teknik analisis data menggunakan uji U Mann - Whitney, untuk melihat perbedaan kondisi kecemasan sebelum dan sesudah diberi perlakuan pada kelompok eksperimen digunakan teknik analisis uji Wilcoxon Rank Test. Hasil analisis menunjukkan $\mathrm{Z}=-1,964$ ( $\mathrm{p}<$ $0,05)$. Tingkat kecemasan kelompok eksperimen lebih rendah $($ mean $=$ 62,33) daripada kecemasan kelompok kontrol (mean $=100,33)$. Khusus pada kelompok eksperimen terbukti bahwa gerakan dalam metode pilates untuk kehamilan efektif menurunkan kecemasan dalam menghadapi kehamilan pertama trimester III $(\mathrm{t}=7,821$; $\mathrm{p}<0,05)$ dengan mean sebelum $=95,00$; mean setelah $=62,33$. Jadi dapat disimpulkan bahwa metode pilates berpengaruh terhadap penurunan kecemasan ibu hamil pertama trimester III.
\end{abstract}

Keyword: Pilates Method, Anxiety pregnant women, third trimester

\title{
Pendahuluan
}

Angka kematian ibu (AKI) dan angka kematian bayi (AKB) di Indonesia tercatat masih cukup tinggi. Berdasarkan Data survey pada tahun 2018 - 2019 menunjukkan angka kematian ibu dan bayi mencapai 305 per 100.000 kelahiran hidup (SDKI, 2019). Penyebab utama kematian ibu umumnya dikarenakan tekanan darah tinggi saat kehamilan (preklamsia), pendarahan saat persalinan, dan gangguan jantung yang menyertai saat persalinan. Mengingat tingginya angka kematian ibu dan bayi, pemerintah telah menyiapkan program khusus seperti penyelamatan pada ibu, dimana program ini memprioritaskan penanganan dan pemberian fasilitas layanan kesehatan prima pada ibu dan anak termasuk pada saat kehamilan dan persalinan hingga 1000 hari setelah melahirkan (Margianto, 2012). 
Kehamilan termasuk salah satu periode krisis dalam proses perkembangan kehidupan seorang perempuan dan merupakan masa yang sulit, khususnya kehamilan pertama (Yanita, 2001). Hal ini karena pada saat seorang wanita hamil, terjadi perubahanperubahan baik fisiologis maupun psikologis. Perubahan secara fisiologis disebabkan oleh terjadinya perubahan hormon yang akan berdampak pula pada perubahan psikologis sehingga menyebabkan perasaan cemas, takut, tetapi sekaligus bahagia (Karanina, 2005). Pada kehamilan pertama, ibu membutuhkan penyesuaian diri terhadap keadaan dirinya dengan segala perubahan yang terjadi, seperti gejala mual-mual, muntah, pusing, bahkan pingsan (Karanina, 2005). Oleh karena kehamilan pertama merupakan pengalaman baru, baik bagi istri maupun suami, maka sering dialami kebingungan khususnya pada istri. Pada umumnya ibu hamil pertama mengeluhkan munculnya perubahan atas pola hidupnya seperti; mengalami batuk tak kunjung sembuh, sering buang air kecil, selalu ingin marah, mual, pusing, berpantang makanan karena berbahaya bagi kondisi janin, harus mencari posisi aman untuk melakukan hubungan seks dengan suami, pekerjaan dan perjalanan yang aman bagi perkembangan janin, serta bagaimana kelak membuka secara alami sewaktu persalinan dan dapat mendorong bayi dengan mudah (Mongan, 2007). Secara psikologis ibu hamil menjadi mudah marah atau tersinggung, gelisah, tidak mampu memusatkan perhatian, ragu-ragu, bahkan kemungkinan ingin lari dari kenyataan hidup.

Pada ibu yang belum pernah hamil dan melahirkan (primigravida), kehamilan dan persalinan merupakan hal asing bagi mereka, apalagi bila pernah mendengar cerita tentang trauma kegagalan dalam menghadapi perubahan-perubahan fisiologis kehamilan dan persalinan, maka hal itu dapat menimbulkan kecemasan (Saleha, 2003). Keadaan serupa tidak terlalu nampak pada ibu yang pernah hamil dan melahirkan (multigravida), karena sudah berpengalaman dalam menghadapi proses perubahan yang terjadi saat kehamilan dan persalinan, sehingga mereka lebih bisa memahami dan menjadi lebih tenang dalam menjalani kehamilan.

Kondisi cemas berlebihan, khawatir dan takut tanpa sebab akan mempersulit proses persalinan. Oleh karena itu kecemasan ibu hamil perlu dikelola agar tidak berkembang ke arah yang tidak dikehendaki. Kondisi cemas yang ditandai dengan adanya otot 
tubuh menegang, dapat menyebabkan otot-otot jalan lahir ikut menjadi kaku dan keras sehingga sulit mengembang, padahal proses kelahiran dapat berlangsung dengan normal dan lancar jika otot-otot jalan lahir bersifat lentur sehingga dapat mengembang sesuai dengan bentuk tubuh bayi. Kecemasan juga dapat menyebabkan emosi tidak stabil yang akan membuat ibu merasakan sakit semakin hebat (Amalia, 2009).

Dengan demikian Ibu hamil yang mengalami kecemasan membutuhkan suatu cara atau keterampilan untuk mengatasi atau mengelolanya. Banyak cara yang bisa dilakukan untuk mengatasi kecemasan pada ibu hamil, salah satunya adalah dengan menggunakan metode pilates. Pilates yang dirancang khusus untuk kehamilan akan membuat ibu hamil lebih fit dan rileks. Berbagai keluhan selama kehamilan, seperti sakit pinggang, kaki bengkak, tegang pada bagian leher, kram dan kesemutan dapat teratasi dengan latihan pilates. Pernapasan juga menjadi lebih teratur dan pada akhirnya momen kehamilan lebih menyenangkan, mood ibu hamil terjaga, bahkan proses persalinan pun terbantukan, sehingga ketika ibu hamil menjalani kehamilannya dengan rileks dan nyaman serta memiliki kondisi yang bugar, mood yang selalu terjaga positif tentunya membuat hamil menjadi lebih tenang dalam menjalani kehamilannya, sehingga kecemasan yang dirasakan oleh ibu hamil dapat berkurang.

\section{Metode Penelitian}

Penelitian ini dilakukan dengan menggunakan metode eksperimen, untuk mengetahui sejauh mana pengaruh Metode Pilates terhadap penurunan kecemasan pada ibu hamil trimester III. Desain eksperimen yang digunakan dalam penelitian ini adalah randomized pretest- posttest control group design, yaitu partisipan dibagi secara acak dalam dua kelompok yaitu kelompok eksperimen dan kelompok kontrol serta dilakukan pengukuran variabel tergantung sebelum dan sesudah diberikan perlakuan. Variabel penelitian yang digunakan adalah Skala Kecemasan Ibu Hamil yang disusun oleh Paramitha (2011), mengacu teori Nevid dkk (2005) melibatkan dua gejala yaitu fisiologis dan psikologis. Jumlah skor yang tinggi pada skala, menunjukkan tingginya 
tingkat kecemasan subjek, sebaliknya semakin rendah jumlah skor pada skala menunjukkan bahwa tingkat kecemasan subjek rendah.

\section{Hasil dan Pembahasan}

Subjek yang digunakan dalam penelitan ini sebanyak 6 (enam) orang dengan kehamilan pertama trimester 3 (tiga), yang kemudian dibagi ke dalam kelompok kontrol dan kelompok eksperimen. Analisis data kuantitatif dilakukan untuk menguji perbedaan tingkat kecemasan kehamilan pada ibu hamil pertama trimester III antara kelompok ekspeimen dengan kelompok kontrol menggunakan selisih skor pretest dan postest (gain score). Teknik analisis menggunakan uji U Mann - Whitney. Untuk melihat perbedaan kondisi kecemasan sebelum dan sesudah diberi perlakuan pada kelompok eksperimen digunakan teknik analisis uji Wilcoxon Rank Test. Selain analisis kuantitatif, penelitian ini juga menggunakan analisis kualitatif hasil wawancara dan dokumentasi lainnya sebagai analisis pelengkap.

setelah kelompok eksperimen diberi perlakuan dengan menggunakan teknik Uji $U$ - Mann-Whitney. Berdasarkan hasil analisis ditemukan nilai $Z$ sebesar $-0,1964$ dan $p=0,025(p<0,05)$. Hasil analisis menunjukkan bahwa ada perbedaan tingkat kecemasan antara kelompok eksperimen yang diberi perlakuan dengan kelompok kontrol yang tidak diberikan perlakuan. Skor kecemasan kelompok eksperimen lebih rendah $($ mean $=62,33)$ daripada kelompok kontrol (mean $=100,33)$. Ringkasan hasil analisis dapat dilihat pada Tabel di bawah ini:

Tabel 1.

Analisis uji U-Mann Whitney

\begin{tabular}{cccc}
\hline & Pre test & Post test & $\begin{array}{c}\text { Gained } \\
\text { Score }\end{array}$ \\
\hline $\mathrm{Z}$ & -.655 & -1.964 & -1.964 \\
Asymp.sig. (2-tailed) & .513 & .050 & .050 \\
\hline
\end{tabular}

Analisis selanjutnya digunakan teknik Wilcoxon Rank Test terhadap kelompok eksperimen, hasilnya menunjukkan skor $\mathrm{Z}$ sebesar $-1,604 ; p=0,109$ ( $p>0,05)$. Berdasarkan hasil uji beda 
dengan menggunakan teknik statistik nonparametrik hasilnya menunjukkan tidak ada perbedaan kecemasan pada kelompok eksperimen antara sebelum dan sesudah diberikan latihan metode pilates untuk kehamilan. Namun berdasarkan statistik parametrik (uji t sampel berpasangan) terlihat ada perbedaan kecemasan pada kelompok eksperimen antara sebelum dan sesudah diberikan perlakuan $(\mathrm{t}=7,821 ; \mathrm{p}<0,05)$, dimana terjadi penurunan kecemasan kelompok eksperimen antara sebelum $($ mean $=95,00)$ dengan sesudah perlakuan (mean $=62,33$ ).

Berikut ini merupakan hasil pengukuran dari keseluruhan subjek, baik pada pre dan post treatment. Data yang digunakan sebagai dasar pengujian hipotesis yaitu data yang diperoleh dari hasil pretest dan posttest data skala kecemasan ibu hamil baik kelompok eksperimen maupun kelompok kontrol. Data pengukuran skala kecemasan ibu hamil secara hipotetik ditemukan skor minimal sebesar 30, skor maksimal sebesar 120, mean sebesar 75 dan standar deviasi sebesar 15.

Secara lebih jelas, pada Tabel berikut ini adalah kategori skor pretest skala kecemasan kelompok eksperimen dan kelompok kontrol.

Tabel 2.

Kategori skor pretest kelompok eksperimen dan kelompok kontrol

\begin{tabular}{|c|c|c|c|c|c|c|}
\hline \multirow{2}{*}{ No. } & \multirow{2}{*}{ Subjek } & \multicolumn{2}{|c|}{ Kelompok eksperimen } & \multirow{2}{*}{ Subjek } & \multicolumn{2}{|c|}{ Kelompok kontrol } \\
\hline & & Skor & Kategori & & Skor & Kategori \\
\hline 1 & D & 101 & Tinggi & $\mathrm{Y}$ & 98 & Tinggi \\
\hline 2 & $\mathrm{~T}$ & 93 & Tinggi & $S$ & 92 & Tinggi \\
\hline 3 & $\mathrm{~L}$ & 91 & Tinggi & M & 102 & Tinggi \\
\hline
\end{tabular}

Berdasarkan perolehan skor dan kategori pada tabel di atas, diketahui bahwa subjek penelitian baik kelompok eksperimen dan kelompok kontrol sebelum diberi perlakuan memiliki tingkat kecemasan tinggi.

Hasil pengukuran secara empirik sebelum kegiatan (pretest) pada kelompok eksperimen ditemukan skor minimal 91, skor maksimal 101, nilai mean 95 dan nilai standar deviasi 5,292. Sedangkan pada kelompok kontrol ditemukan skor minimal 92, skor maksimal 102, nilai mean 97,33 dan standar deviasi 5,033. Hasil pengukuran secara empirik setelah kegiatan (posttest) pada 
kelompok eksperimen ditemukan skor minimal 60, skor maksimal 65, nilai mean 62,33 dan nilai standar deviasi 2,517. Pada kelompok kontrol ditemukan skor minimal 98, skor maksimal 103, nilai mean 100,33 dan nilai standar deviasi 2,517. Hasil pengukuran ulang satu minggu setelah kegiatan (follow up) pada kelompok eksperimen ditemukan skor minimal 41, skor maksimal $=48$, nilai mean 43,67 dan nilai standar deviasi 3,786. Deskripsi data penelitian secara singkat dapat dilihat pada Tabel di bawah ini:

\section{Tabel 3.}

Deskripsi data hipotetik dan empirik penelitian

\begin{tabular}{|c|c|c|c|c|c|c|}
\hline \multirow{3}{*}{ Pengukuran } & \multicolumn{5}{|c|}{ Data Empirik } & \multirow{3}{*}{$\begin{array}{c}\text { Data } \\
\text { Hipot } \\
\text { etik }\end{array}$} \\
\hline & \multicolumn{3}{|c|}{$\begin{array}{l}\text { Kelompok Eksperimen } \\
(\mathrm{N}=3)\end{array}$} & \multicolumn{2}{|c|}{$\begin{array}{l}\text { Kelompok kontrol } \\
\quad(\mathrm{N}=3)\end{array}$} & \\
\hline & $\begin{array}{l}\text { Pre } \\
\text { test }\end{array}$ & $\begin{array}{c}\text { Post } \\
\text { test }\end{array}$ & $\begin{array}{c}\text { Follow } \\
\text { up }\end{array}$ & Pre test & Post test & \\
\hline Minimal & 91 & 60 & 41 & 92 & 98 & 30 \\
\hline Maksimal & 101 & 65 & 48 & 102 & 103 & 120 \\
\hline Mean & 95 & 62,33 & 43,67 & 97,33 & 100,33 & 75 \\
\hline SD & $\begin{array}{c}5,29 \\
2\end{array}$ & 2,517 & 3,786 & 5,033 & 2,517 & 15 \\
\hline
\end{tabular}

Ket: $\mathrm{SD}=$ standar deviasi

Dari hasil deskripsi data di atas, dapat disimpulkan bahwa skor data posttest yang diperoleh kelompok eksperimen lebih kecil (kategori sedang) dari skor data posttest yang diperoleh kelompok kontrol (kategori tinggi), dan skor data follow up pada kelompok eksperimen mengalami penurunan dibandingkan pada saat posttest Secara lebih jelas, pada Tabel 4 berikut ini adalah kategori skor posttest skala kecemasan kelompok eksperimen dan kelompok kontrol dan pada Tabel 5 merupakan kategori skor follow up skala kecemasan kelompok eksperimen. 
Tabel 4.

Kategori skor posttest kelompok eksperimen dan kelompok kontrol

\begin{tabular}{ccccccc}
\hline \multirow{2}{*}{ No. } & \multirow{2}{*}{ Subjek } & \multicolumn{2}{c}{ Kelompok eksperimen } & \multirow{2}{*}{ Subjek } & \multicolumn{2}{c}{ Kelompok kontrol } \\
\cline { 3 - 4 } \cline { 7 - 7 } & Skor & Kategori & & Skor & Kategori \\
\hline 1 & $\mathrm{D}$ & 60 & Sedang & Y & 100 & Tinggi \\
2 & $\mathrm{~T}$ & 65 & Sedang & $\mathrm{S}$ & 101 & Tinggi \\
3 & $\mathrm{~L}$ & 62 & Sedang & $\mathrm{M}$ & 103 & Tinggi \\
\hline
\end{tabular}

Tabel 5.

Kategori skor posttest dan follow up kelompok eksperimen

\begin{tabular}{|c|c|c|c|c|c|c|}
\hline \multirow[t]{2}{*}{ No. } & \multirow[t]{2}{*}{ Subjek } & \multicolumn{2}{|c|}{$\begin{array}{c}\text { Kelompok eksperimen } \\
\text { posttest }\end{array}$} & \multirow[t]{2}{*}{ Subjek } & \multicolumn{2}{|c|}{$\begin{array}{l}\text { Kelompok } \\
\text { eksperimen } \\
\text { follow up }\end{array}$} \\
\hline & & Skor & Kategori & & Skor & Kategori \\
\hline 1 & $\mathrm{D}$ & 60 & Sedang & $\mathrm{D}$ & 41 & Rendah \\
\hline 2 & $\mathrm{~T}$ & 65 & Sedang & $\mathrm{T}$ & 48 & Rendah \\
\hline 3 & $\mathrm{~L}$ & 62 & Sedang & $\mathrm{L}$ & 42 & Rendah \\
\hline
\end{tabular}


Jika divisualisasikan dengan grafik, maka perubahan skor kecemasan itu nampak dengan jelas. Gambar berikut ini memerlihatkan dengan jelas perubahan skor kecemasan yang dialami setiap subjek pada kelompok eksperimen dan kelompok kontrol.

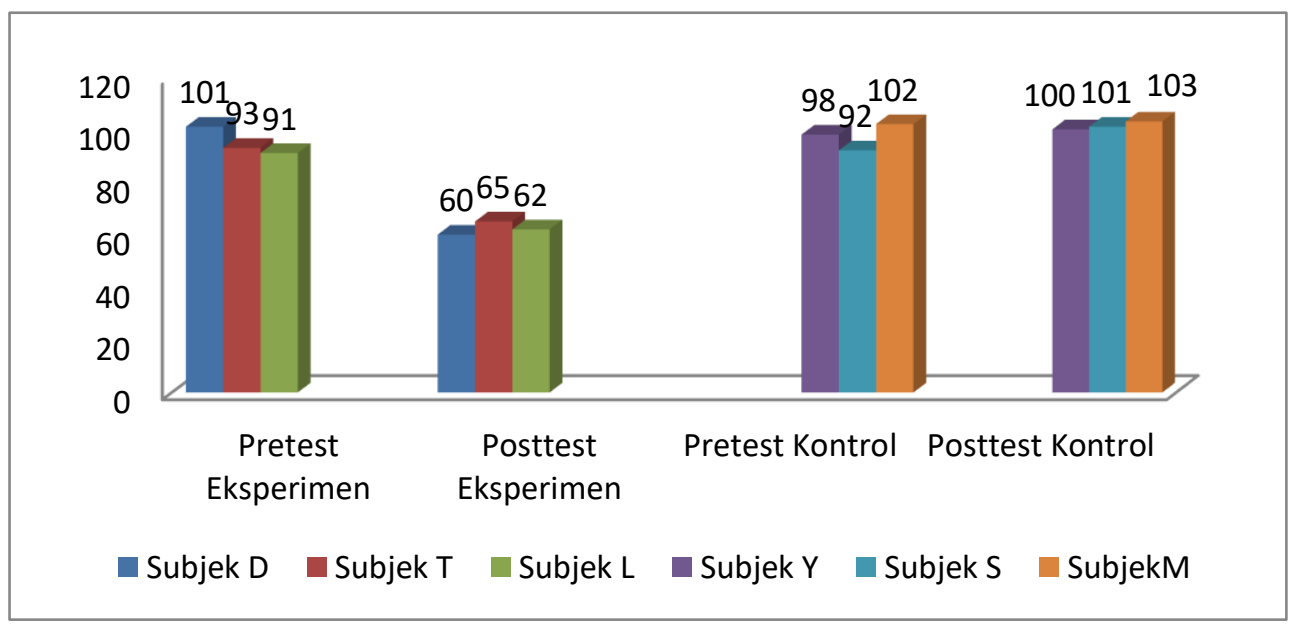

\section{Gambar 1. \\ Grafik skor pretest dan posttest pada kelompok eksperimen dan kelompok kontrol}

Berdasarkan data yang didapat membuktikan bahwa kelompok ibu hamil yang mendapatkan latihan gerakan pilates untuk kehamilan memiliki kecemasan yang lebih rendah dibandingkan dengan kelompok ibu hamil yang tidak mendapatkan latihan gerakan pilates untuk kehamilan. Dari analisis data kuantitatif didapatkan hasil $\mathrm{Z}=-1,964 ; \mathrm{p}<0,05$ yang menunjukkan ada perbedaan tingkat kecemasan ibu hamil pertama trimester III antara subjek kelompok eksperimen dengan subjek kelompok kontrol. Tingkat kecemasan kelompok eksperimen lebih rendah $($ mean $=62,33)$ daripada kecemasan kelompok kontrol $($ mean $=$ 100,33). Khusus pada kelompok eksperimen terbukti bahwa gerakan dalam metode pilates untuk kehamilan efektif menurunkan kecemasan dalam menghadapi kehamilan pertama 
trimester III $(\mathrm{t}=7,821 ; \mathrm{p}<0,05)$ dengan mean sebelum $=95,00$; mean setelah $=62,33$; mean follow up $=43,67$.

Data di atas diperkuat dengan hasil analisis kualitatif bahwa subjek kelompok eksperimen mengalami penurunan kecemasan. Perbedaan antara kedua kelompok tersebut dikarenakan adanya pemberian perlakuan khusus dimana pada kelompok eksperimen diberikan latihan gerakan pilates untuk kehamilan yang dilakukan selama empat kali dalam waktu dua minggu. Pemberian gerakan dalam metode pilates untuk kehamilan dapat mengurangi kecemasan yang dialami oleh ibu hamil, dimana kecemasan ini mengakibatkan ketidak nyamanan dalam menjalani kehamilan, ketakutan akan rasa sakit pada saat menghadapi persalinan, ketegangan pada otot, pegal, keram, susah tidur dan lain sebagainya. Hal ini senada dengan yang diungkapkan oleh subjek bahwa sebelum mengikuti latihan pilates subjek mengalami keluhan-keluhan tersebut dan setelah mengikuti pelaksanaan latihan pilates sebanyak empat kali selama dua minggu subjek merasa dirinya lebih nyaman dan tenang dalam menjalani kehamilannya.

Pemberian gerakan dalam metode pilates untuk kehamilan dapat mengurangi kecemasan yang dialami oleh ibu hamil, dimana kecemasan ini mengakibatkan ketidaknyamanan dalam menjalani kehamilan, ketakutan akan rasa sakit pada saat menghadapi persalinan, ketegangan pada otot, pegal, keram, susah tidur dan lain sebagainya. Hal ini senada dengan yang diungkapkan oleh subjek bahwa sebelum mengikuti latihan pilates subjek mengalami keluhan-keluhan tersebut dan setelah mengikuti pelaksanaan latihan pilates sebanyak empat kali selama dua minggu subjek merasa dirinya lebih nyaman dan tenang dalam menjalani kehamilannya. Menurut Rafknowledge (2004), perubahan fisik pada ibu hamil trimester III dapat membuat perasaan tidak nyaman yang disebabkan karena perut yang semakin membesar, kadang terasa panas, banyak buang air kecil di malam hari, nyeri punggung, kaki bengkak, kram, tegang dan kaku pada leher. Hal tersebut membuat ibu hamil kesulitan tidur dan membuat dirinya tidak nyaman. 
Keefektifan metode pilates untuk mengurangi kecemasan pada ibu hamil didukung oleh penelitian yang dilakukan Khalajzadeh, dkk (2012) yang menyatakan bahwa yoga efektif untuk menurunkan kecemasan pada ibu hamil trimester II dan III. Dimana dalam hal ini yoga merupakan dasar yang diambil dalam gerakan pilates yang disetiap gerakannya terkandung unsur relaksasi (King \& Green, 2002).

Menurut Namuri (2011), bahwa dengan melakukan gerakan pilates dapat menjaga kondisi tubuh selalu bugar, rileks, mood positif ibu hamil selalu terjaga, serta menyetabilkan ketegangan fisik dan emosi yang dialami ibu hamil saat menjalani kehamilan maupun saat menghadapi persalinan. Metode pilates dapat juga digunakan sebagai media untuk mengatasi depresi, memulihkan ketegangan pada otot, membuat setiap persendian pada tubuh lebih fleksibel, melancarkan peredaran darah, dan dapat mengurangi stres serta kecemasan dimana umumnya lebih sering dialami oleh ibu hamil terutama memasuki trimester ketiga.

Kecemasan berkaitan dengan serotonin, dimana serotonin merupakan hormon yang berada di mocus membran yang memiliki fungsi mengatur sistem saraf pusat dan menghubungkannya dengan neurotransmiter sehingga secara signifikan dapat mengatur mood individu, perhatian, konsentrasi dan gerakan tubuh. Fungsi lain dari serotonin adalah untuk pengaturan pola tidur, suhu tubuh, perilaku sosial, proses belajar, memori, fungsi endokrinal, kecemasan, depresi, mood serta fungsi kardiovaskular (Abdel, Hasan \& Amin, 2011).

Pilates yang diberikan untuk ibu hamil pertama trimester ketiga bertujuan untuk mengurangi kecemasan yang dialami. Pada usia kehamilan yang mendekati masa persalinan, ibu hamil sering mengeluhkan ketegangan fisik yang dirasakan seperti merasa tegang pada otot leher, punggung, rasa keram, sulit menentukan posisi tidur karena kehamilan yang semakin membesar, sulit mengontrol perasaan, dan sering memikirkan hal yang membuat dirinya takut, bahkan perasaan tersebut muncul tanpa alasan yang jelas. Gerakan dalam metode pilates untuk kehamilan yang telah dilaksanakan dapat membawa efek rileks pada tubuh ibu hamil, nyaman dalam menjalani minggu-minggu terakhir kehamilannya serta tentunya dapat menurunkan kecemasan. 
Melemasnya otot ini berhubungan dengan meningkatnya kinerja saraf parasimpatetik yang diperoleh dari situasi yang tenang dan rileks saat melakukan latihan pernafasan. Ketika ibu hamil melakukan pengaturan nafas yang benar maka secara otomatis ritme kerja jantung menjadi teratur sehingga jantung mampu memompa darah yang kaya akan oksigen secara maksimal dan mengalirkannya ke seluruh tubuh, dalam keadaan seperti itu sistem saraf otonom berkontribusi besar karena bertugas mengendalikan kelenjar-kelenjar dan otot halus, termasuk jantung, pembuluh darah, dan lapisan perut serta usus, selain itu sistem saraf otonom berfungsi untuk menghubungkan sistem saraf pusat dengan kelenjar endokrin (Kalat, 2010). Secara psikologis, sistem saraf ini sangat mempengaruhi dinamika emosi, perasaan dan suasana hati. Bila ibu hamil melakukan latihan tersebut dengan benar, maka ibu hamil akan merasakan efeknya yang akan berguna untuk mengatasi tekanan atau ketegangan yang dirasakan selama kehamilan (Pia, 2007).

Unsur relaksasi yang terkandung dalam gerakan pilates akan meningkatkan kinerja saraf parasimpatetik dan menghambat peningkatan kinerja saraf simpatetik, sehingga hormon penyebab disregulasi tubuh dapat dikurangi jumlahnya. Akibatnya akan terjadi penurunan detak jantung, irama nafas, tekanan darah, ketegangan otot, dan tingkat metabolisme. Seiring penurunan tersebut akan meningkatkan kesehatan, penyembuhan, penguatan dan peremajaan (Domin, 2001).

Melalui gerakan pilates diharapkan ibu hamil mampu memunculkan respon rileks sehingga dapat menimbulkan rasa lebih nyaman dan lebih tenang (Namuri, 2011). Respon rileks tersebut terjadi karena adanya penurunan bermakna dari kebutuhan zat oksigen oleh tubuh, aliran darah menjadi lancar, denyut jantung menjadi normal, neurotransmitter penenang akan dilepaskan, sistem saraf akan bekerja dengan baik, otot - otot tubuh yang tegang menjadi kendur dan pernafasan menjadi teratur (Paramitha, 2010).

Keadaan seperti ini membuat kondisi fisik menjadi lebih sehat, dengan tubuh yang bugar dan prima tentunya membuat ibu hamil menjadi lebih nyaman dan tenang dalam menjalani kehamilannya, selain itu pikiran-pikiran negatif yang sering muncul dan dibayangkan oleh ibu hamil seperti sakitnya proses 
persalinan, mampu atau tidak melakukan persalinan secara normal, kuat atau tidaknya nanti dalam mengejan akan dapat diatasi. Pikiran negatif tersebut merupakan hasil dari perspektif kognitif yang berperan sebagai cara berpikir yang terdistorsi dan disfungsional yang memegang peran pada pengembangan persepsi terhadap suatu ancaman yang berasal dari sinyal internal atau eksternal mengarah pada perasaan khawatir atau kecemasan yang disertai dengan aktivasi dari sistem saraf simpatis yang menyebabkan pelepasan epinefrina (adrenalin) oleh kelenjar adrenal dan mengintensifkan sensasi fisik dengan terjadinya peningkatan denyut jantung, nafas cepat, dan berkeringat (Nevid, dkk, 2005).

Ibu hamil yang melakukan latihan pilates secara rutin dapat meningkatkan keyakinan pada dirinya bahwa ia bisa melewati dengan baik masa kehamilannya (Pia, 2007), dan merubah pikiran negatif yang sebelumnya sering muncul menjadi positif. Hal ini dikarenakan saat melakukan latihan pilates, sensasi fisik yang diaktivasi oleh saraf simpatis ditekan oleh meningkatnya kinerja saraf parasimpatis yang berimbas pada terjadinya pelemasan otototot tubuh, penurunan denyut jantung, normalnya ritme nafas dan lancarnya peredaran darah ke seluruh tubuh akibatnya ibu hamil akan berada pada kondisi rileks, tenang dan nyaman (Domin, 2001). Kondisi tersebut tentunya akan membuat ibu hamil lebih siap dalam menghadapi persalinannya.

Dalam penelitian ini gerakan dalam metode pilates untuk kehamilan terbukti dapat menurunkan kecemasan ibu hamil pertama trimester III, baik secara fisik maupun psikis. Inti dari latihan pilates untuk kehamilan adalah untuk menguatkan otot otot sendi, terutama otot bagian perut dan dekat tulang belakang, sehingga ibu hamil dapat menjalani kehamilannya dengan lebih nyaman dan dapat membantu proses persalinannya nanti. Hal ini sesuai dengan yang diungkapkan oleh Namuri (2011), bahwa pilates berguna untuk melatih napas, merilekskan pikiran, dan melancarkan peredaran darah. 


\section{Simpulan dan Saran}

Berdasarkan hasil dari penelitian dan pembahasan dapat disimpulkan bahwa ada perbedaan tingkat kecemasan pada kehamilan pertama trimester III antara kelompok eksperimen yang mendapatkan perlakuan berupa gerakan dalam metode pilates untuk kehamilan dan kelompok kontrol yang tidak mendapatkan perlakuan. Tingkat kecemasan kelompok eksperimen lebih rendah daripada kecemasan kelompok kontrol. Khusus pada kelompok eksperimen terbukti bahwa gerakan dalam metode pilates untuk kehamilan efektif menurunkan kecemasan dalam menghadapi kehamilan pertama trimester III. Dalam penelitian ini gerakan dalam metode pilates untuk kehamilan terbukti dapat menurunkan kecemasan ibu hamil pertama trimester III, baik secara fisik maupun psikis. Gerakan dalam metode pilates dapat digunakan untuk memerkuat otot, meningkatkan fleksibilitas sendi dan bekerja untuk merangsang sirkulasi darah, mengurangi stres serta kecemasan dan meningkatkan kadar serotonin yang merupakan kunci untuk mengatur perasaan, emosi serta berpengaruh terhadap kecemasan dan depresi.

Atas dasar hasil penelitian ini, maka Pemberian latihan pilates untuk kehamilan ini dapat direkomendasikan dan disosialisasikan kepada ibu hamil lainnya agar dalam menjalani kehamilannya dapat dilalui dengan nyaman dan tenang.

Bagi klinik bersalin terkait, hasil dari penelitian ini dapat dijadikan pertimbangan agar dapat memberikan layanan pilates untuk kehamilan sebagai salah satu fasilitas untuk ibu hamil di klinik tersebut.

Bagi peneliti selanjutnya demi mengembangkan pilates yang telah terbukti efektif dalam menurunkan kecemasan pada kehamilan, disarankan untuk melakukan penelitian mengenai efektifitas pilates dalam penurunan kecemasan tentunya dengan karakteristik subjek yang berbeda dari yang telah peneliti lakukan. 


\section{Referensi}

Abdel, E., Hasan, A., \& Amin, M. A. (2011). Pilates exercise influence on the serotonin hormone, some physical variable and the depression degree in battered women. World Journal of Sport Science, 5 (2): 89-100.

Amalia, T. (2009). Kecemasan ibu menanti persalinan. (http://titianamalia.wordpress.com/2013/06/16/kecemasanibu-menanti-persalinan). Diakses pada tanggal 16 Juni 2013.

Domin, V. 2001. Relaxation-How good are you at relaxation?. (http://www. books.google.co.id). Diakses pada tanggal 15 April 2014.

Kalat, J.W. (2010). Biopsikologi. Edisi 9. Jakarta. Salemba Humanika.

Karanina, S. D., Suyasa, P. T. (2005). Hubungan persepsi terhadap dukungan dan penyesuaian diri istri pada kehamilan anak pertama. Jurnal Pronesis, 7: 79-101.

Khalajzadeh, M., Masoumeh, S., \& Mani, M. (2012). The effect of yoga on anxiety among pregnant women in second and third trimester of pregnancy. European Journal of Sport and Excercise Science, 1 (3): 85-89.

King, M., \& Green, Y. (2002). Pilates for pregnancy. Canada: Octopus Publishing Group Limited.

Mongan, M. F. (2007). Hypnobirthing the mongan method. Metode melahirkan secara aman, mudah dan nyaman. Jakarta: PT. Bhuana Ilmu.

Namuri, L. (2011). Pilates untuk kehamilan. Jakarta : Dian Rakyat 
Nevid, J. S., Rathus, S. A., \& Greene, B. (2005). Psikologi abnormal. Jilid 2. Jakarta : Erlangga.

Pia, S. D. (2007). Pilates and pregnancy : Programming ideas and exercise guidelines. Idea Fitness Journal, 1: 89-92.

Saleha. (2003). Hubungan tingkat pengetahuan ibu primigravida tentang kehamilan dan persalinan dengan tingkat kecemasan di wilayah kerja puskesmas Gombong II.( http://proposalpenelitian.blogspot.com). Diakses pada tanggal 28 Agustus 2013.

Yanita. A., \& Zumralita. (2001). Persepsi perempuan primipara tentang dukungan suami dalam usaha menanggulangi gejala depresi pascasalin. Phornesis Jurnal Ilmiah dan Terapan. 3: 23-30. 